\title{
TRAINING MANAGEMENT OF APPRENTICESHIP PROGRAM: A COMPARISON OF EXPECTATION THEORY, SELF DETERMINATION THEORY, AND SOCIAL IDENTITY THEORY
}

\author{
Muh. Tamrin \\ Ph.D scholar, Post Graduate School of Economics \\ Hasanuddin University \\ South Sulawesi, Indonesia
}

Mahlia Muis

Professor of Economics, Post Graduate School of Economics

Hasanuddin University

South Sulawesi, Indonesia

Idayanti Nursyamsi

Professor of Economics, Post Graduate School of Economics

Hasanuddin University

South Sulawesi, Indonesia

\section{Sumardi}

Ph.D of Economics, Post Graduate School of Economics

Hasanuddin University

South Sulawesi, Indonesia

DOI: 10.31364/SCIRJ/v6.i12.2018.P1218597

http://dx.doi.org/10.31364/SCIRJ/v6.i12.2018.P1218597

\begin{abstract}
Expectation theory, self-determination theory, and social identity theory are prominent theories in training management research. Each theory results in different style of management. The theories also related to corresponding organizational culture to support the training. In this article, we compare the theories to find the best theory to fit with apprenticeship program in private sector context in Indonesia. We compare the management styles and associated organizational culture from four mining companies in South Sulawesi Indonesia, consisting of total 250 trainees. Best management style should be results in best model and significant relationships across components of training (training curriculum, training process, training effectiveness, and job performance) and across organizational cultures. Without looking at organizational culture, the best management training is training management based on the self determination theory. Training management based on the self determination theory is able to give effect to the process and effectiveness of training as well as on employee performance. Results suggest self-determination theory as the basis for management across any types of organizational culture.
\end{abstract}

Index Terms - training management, apprenticeship program, organizational culture, self-determination theory

\section{INTRODUCTION}

Previous studies found that apprenticeships programs have medium-term financial benefit to the company (Mazenod, 2016). Companies involved in apprenticeship activities are motivated by confidence in the curriculum available in this program to get qualified new employees (Mazenod, 2016). Despite the growing use of the apprenticeship as a source for education or training for new employees to prepare it for the company's first job, practitioners are still confused about how to motivate trainees so that the program can have a maximum effect on employee performance. 
Training management is the management and implementation of training (Bondarouk \& Ruel, 2010). Training management is an important element of human resource development because it determines the direction in improving organizational performance using training. The position of the training manager in the hands of professionals has a better impact than the training that is in the hands of partners, let alone not being paid (Carvalho, Melo, \& Ferreira, 2016).

In this training management, the issue of motivation for participants is an important issue because motivation theory is used to manage and carry out training. Motivation is related to psychological factors that encourage trainees to be involved. Motivation is also known to encourage not only the training process, but also the transfer of training. The question then is what is a company's managerial step based on this theory? There are many theories to choose, depending on what beliefs are held by managers in managing training. This belief will not be separated from the theory held as a basis for motivating trainees and orientation to organizational culture, because managers are part of the organization, and its status as a manager shows that he has long lived in it and can reach managerial positions because of the internalization of the organizational culture he or she hold.

Typically, theoretical approaches for training management takes three branches: expectation theory, self determination theory, and social identity theory. Vroom's expectancy theory states that a person's motivation for training transfers depends on the calculation of the profit and loss that can be obtained by the individual (Bjerregaard, Haslam, \& Morton, 2016). Self-determination theory (Ryan \& Deci, 2000) considers that the process and transfer of training can be encouraged if there is a strong intrinsic motivation in employees. Meanwhile, social identity theory states that process and training transfer motivational factors are social group identities (Bjerregaard et al, 2016).

Accordingly, the primary objective of this study is to find out what theories are most suitable for underpinning the training management of the apprenticeship program. The influence of the related training management will be examined in a number of models to find which management model can apply generally to all organizational cultures and provide the greatest effect on the process and outcomes of training (training effectiveness and employee performance).

Previous research has very little lead to the influence of organizational culture on the effectiveness of training (Palthe \& Kossek, 2003). However, there is a relationship between value, as a part of organizational culture, and effectiveness of HR management actions, including training (Ferris, Hochwarter, Buckley, Harrell-Cook, \& Frink, 1999). We extend this lines with proposing that the effects of organizational culture on training depends on what management styles used to motivating trainees.

\section{LITERATURE REVIEW}

\section{Theories on Training Management}

Management training aims to produce effective learning transfers for trainees. For participants, training transfers are determined by training motivation (Gil, Molina, \& Ortega, 2016). Therefore, it is important for training manager to act based on a clear theory of motivation. Theories on motivation are very diverse. The three theories commonly used in training management are Vroom's expectations theory (Elangovan \& Karakowsky, 1999), self-determination theory (Lacerenza, Reyes, Marlow, \& Joseph, 2017), and social identity theory (Andersson, 2012). All three theories have been used to explain how the output of training can arise in relation to the motivation of the trainees.

The Vroom's expectation theory states that individuals make decisions based on various alternative behaviors. Self motivation is interpreted as a force that directs various alternatives. This theory proposes three concepts, expectations, instrumentality, and valence (Chiang, Jang, Canter, \& Prince, 2008). Expectation is a perception of the possibility that the business will bring good results. This concept is relevant to the concept of attitude in the theory of planned behavior (Ajzen, 1991). Meanwhile, instrumentality is the perception of the possibility that good performance leads to the desired results. Measured instrumentalities ranging from performance will move away from results, performance is not related to results, and performance will drive these results (Dodge \& Ramsey, 1981). Finally, valence is the value given by individuals to incentives obtained from these results.

The application of motivation theory to training management will focus on efforts to show employees that they are making large profits, exceeding their investment in business to take part in training. Training management should be in the hands of the most authoritative officials on incentive issues, such as appraisers or managers who provide salaries to their employees, rather than professionals in the training field. Self-determination theory from Ryan and Deci (2000) conceptualizes that humans are motivated by external factors and internal factors. External factors come from outside the work while internal factors originate from the work itself. Internal factors are seen as having the strongest motivation rather than external factors.

Furthermore, self-determination theory offers three things that can be developed in training to encourage employee selfdetermination. These three things are competence, relevance, and autonomy (Swanson \& Holton, 2001). These three things are the intrinsic motives for employees and are united in the concept of autonomy support. Autonomy is the freedom that employees have. Autonomy can be achieved by seeing that training is not a coercive obligation but provides opportunities for employees to fill their needs (Dysvik \& Kuvaas, 2008). In the training process, autonomy is supported through minimum pressure (evaluation, deadlines, supervision, visible incentives), choices, ability to make decisions and initiatives, and take the perspective of others (Gagne, 2012). Competence is the feeling of being able to do something, in line with the concept of self-efficacy. Competence is achieved when individuals are encouraged to seek optimal challenges according to their capacity and continue to strive to maintain their skills (Dysvik and Kuvaas, 2008). This can also be implemented through providing information and reasons for training, optimal challenges, reasonable goals, and constructive feedback (Gagne, 2012). Relevance are the need to build social relations. Relevances 
are built when employees see a supportive training environment (Dysvik and Kuvaas, 2008). Relevancies are supported by regular meetings, support for collaborating, sharing information and experience, and acknowledging feelings (Gagne, 2012).

The implication of social identity theory in training is designing a curriculum that allows all individuals to see that they are part of a single entity, rather than separate them through segmentation or division based on merit. That is, social identity theory will reject training that assesses the results of training based on individuals, but encourages training to conduct group-based assessments. Maybe some employees who are performing poorly will not be identified, but because they are not detected, they are actually encouraged to be better and develop themselves voluntarily so that their identification becomes more assertive in the group. In line with this, trainers and organizations must see that trainees are a group, not a collection of unrelated individuals (Korte, 2007).

\section{Training Management and Organizational Culture}

Organizational culture is "a pattern of basic assumptions, beliefs, and core values held, and used as a framework for interpreting what happens and solving problems of external adaptation and internal integration" (Vijayakumar \& Padma, 2014, p. 42). There are many organizational culture theories that attempt to map a number of types of organizational culture. The competing values framework sees that organizational culture can be mapped in two dimensions: focus dimensions (internal-integrative vs. externaldifferentiation) and dynamics dimensions (flexible-decretive vs. stable-control). The four combinations of culture produced are clan culture, adocratic culture, market culture, and hierarchical culture (Vijayakumar and Padma, 2014). Table 1 outlines the elements of each culture in this typology.

Table 1. Types of Organizational Culture

\begin{tabular}{|c|c|c|c|c|}
\hline & Clan & Adhocracy & Market & Hierarchy \\
\hline Focus & Internal - integration & External - differentiation & External - differentiation & Internal - integration \\
\hline Dynamics & Flexible - discretion & Flexible - discretion & Stable - control & Stable - control \\
\hline $\begin{array}{l}\text { Work } \\
\text { environment }\end{array}$ & $\begin{array}{l}\text { Family-like with caring } \\
\text { climate }\end{array}$ & Risk taking & $\begin{array}{l}\text { Competition and } \\
\text { achievement oriented }\end{array}$ & $\begin{array}{l}\text { Controlled and } \\
\text { structured }\end{array}$ \\
\hline Leader & Paternalistic & Visionary and innovative & $\begin{array}{l}\text { Aggressive and result } \\
\text { oriented }\end{array}$ & $\begin{array}{l}\text { Bureaucracy and } \\
\text { efficiency oriented }\end{array}$ \\
\hline Norms & $\begin{array}{l}\text { Employees must work as } \\
\text { a group, consensus } \\
\text { building, and participation }\end{array}$ & $\begin{array}{l}\text { Employees must dare to take } \\
\text { risks, innovate, think outside the } \\
\text { box, and creating new } \\
\text { challenges }\end{array}$ & $\begin{array}{l}\text { Employees must } \\
\text { compete, achieve, and } \\
\text { reach even more targets }\end{array}$ & $\begin{array}{l}\text { Employees must } \\
\text { follow rules and } \\
\text { formal policies and } \\
\text { obey to clear tasks and } \\
\text { responsibilities }\end{array}$ \\
\hline Core values & $\begin{array}{l}\text { Loyalty, trust, openness, } \\
\text { individual development }\end{array}$ & $\begin{array}{l}\text { Freedom, uniqueness, } \\
\text { commitment to innovation, } \\
\text { ambiguity and uncertainty } \\
\text { tolerance }\end{array}$ & $\begin{array}{l}\text { Competitive-ness, } \\
\text { achievement, victory }\end{array}$ & $\begin{array}{l}\text { Security, conformity, } \\
\text { predictability, } \\
\text { stability, permanence, } \\
\text { obedience }\end{array}$ \\
\hline Job evaluation & $\begin{array}{l}\text { Human resource } \\
\text { development, } \\
\text { cooperation, and caring }\end{array}$ & $\begin{array}{l}\text { Unique and new products and } \\
\text { services }\end{array}$ & $\begin{array}{l}\text { Market share } \\
\text { achievement and } \\
\text { winning competition }\end{array}$ & $\begin{array}{l}\text { Reliable, efficient, and } \\
\text { cost effective }\end{array}$ \\
\hline
\end{tabular}

Source: modified from Vijayakumar dan Padma (2014)

From table 1 it can be seen that social identity theory will fit in clan culture because both of them prioritize the social aspects of humans. As suggested by social identity theory, employees in clan culture will work as a group and trust each other.

\section{RESEARCH METHODS}

\section{Samples}

Samples $(n=250)$ were collected from apprenticeship program participants at four mining companies in South Sulawesi, Indonesia. Responses were anonymous and participation was voluntary. Researcher visited the companies and personally administered all surveys. Seventy respondents indicated their last education level as post-secondary education. Of the 250 respondents, $93 \%$ was male, $83 \%$ was $0-2$ years in tenure, followed $17 \%$ was 3-5 years in tenure. Largest portion of the respondents worked as operator (43\%), followed by firefighters (18\%), and mechanics (16\%).

\section{Measures}


Organizational culture measured with 12-item developed by Racelis (2005), divided into three dimensions: Clan, adhocracy, and market. Sample items from this scale are "The value that unites my company is loyalty and tradition" and "My company emphasizes competition and work performance". All survey items had a 5-point response format with higher scores representing higher inclination to respective culture (market, clan, and adhocracy). Internal consistency reliability for the scale score was 0.64 for clan culture, 0.66 for adhocracy, and 0.68 for market culture.

Training curriculum was measured with eight items from Pruekpramool \& Sangpradit (2016). All survey items had a 5-point response format with higher scores representing higher curriculum quality. Two sample items from this scale are "Learning material is useful and in accordance with what is trained" and "the trainer looks very skilled in his field". Alpha coefficient for the scale scores was 0.80 .

Training management was measured with 9-item scale developed for three types of training management: expectancy-based, self determination-based, and social identity-based. All survey items had a 5-point response format with higher scores representing higher orientation to respective theory. Sample from expectancy-based scale is "The trainer is a manager in our company". A sample from self-determination training management scale is "The coach motivates participants based on our individual characteristics". Sample for social identity-based training management scale is "the trainer treats all participants as one group equally". Alpha coefficient for the scale scores was 0.722 for expectancy-based scale, 0.621 for self-determination-based scale, and 0.660 for social identity-based scale.

Training process was measured with 10 items (Heaney, 1991). All survey items had a 5-point response format with higher scores representing higher training process quality. A sample item from this scale scale is "in apprenticeship program, we help each other so that all participants understand each other". Coefficient alpha for the scale scores was 0.91 .

Training effectiveness was measured with 3 -item scale developed by Crow (2007), adapted for apprenticeship program. All survey items had a 5-point response format with higher scores representing higher training effectiveness. The sample item from the scale is "based on the apprenticeship program that I received, I can work effectively at the job from the first time". Alpha coefficient for the scale scores was 0.85 .

Job performance was measured with 6 items (Reio Jr, 1997). All survey items had a 5-point response format with higher scores representing higher job performance. A sample item from this scale scale is "compared to senior employees, how is your knowledge and technical skills?". Coefficient alpha for the scale scores was 0.92 .

\section{Hypothesis}

\section{Hypothesis 1: clan culture is the best organizational culture for social identity-based training management}

Self determination theory confirms the aspects of autonomy, competence, and relevance. All three lead to different cultural elements. The aspect of autonomy means the importance of the value of freedom, which is found in the culture of adocracy. But the competency element is in the value of achievement that exists in the market culture. Elements of interconnection, are in clan culture because they are socially oriented. Elements of competency, however, also exist in the culture of adocracy, because without high competence, it is difficult to get innovation or ventured to take risks without having sound calculation. Innovation also requires group work because new developments are difficult for one person to produce. Based on these considerations, we can emphasize the culture of adocracy as a culture suitable for the self-determination style of management.

\section{Hypothesis 2: adhocracy culture is the best organizational culture for self-determination-based training management}

Theory of expectations is economically oriented and of all existing cultures, market culture and hierarchy are very economical cultures. The difference lies in the orientation direction. Market culture is oriented externally, that is on the market or competitive environment, while hierarchical culture is oriented inward, namely efficiency and cost savings. But a hierarchical culture will be difficult to accept expectations because cost savings at the organizational level means minimal benefits for employees. In order for employees to get large profits, the economic orientation of the company must be directed outward. Employees who excel, meaning that they perform well, will get a bonus for their achievements and wins. That is, the culture that best fits the expectations theory is the market culture.

\section{Hypothesis 3: market culture is the best organizational culture for expectancy-based training management}

The primary objective of this study is to find out what theories are most appropriate for underpinning the training management of the apprenticeship program. From this objective, we made no hypothesis, making the analysis completely exploratory. The best theory should better relates to process and output variables of training, for all models involving other cultures than its determined culture, compared to other theories.

\section{RESULTS AND DISCUSSION}

Table 2 shows the intercorrelations between research variables. Consistent with previous assumptions, job performance is positively and significantly correlated with culture, curriculum, management, process and effectiveness of training. The effectiveness 
of training also positively correlated with the training process $(r=0.57, \mathrm{p}<0.01)$, indicating the potential influence of the training process on the effectiveness of the training.

Table 2. Intercorrelations among the Study Variables

\begin{tabular}{|c|c|c|c|c|c|c|c|c|c|c|}
\hline & & 1 & 2 & 3 & 4 & 5 & 6 & 7 & 8 & 9 \\
\hline 1 & Clan culture & & & & & & & & & \\
\hline 2 & Adhocracy culture & $.54^{* *}$ & & & & & & & & \\
\hline 3 & Market culture & $.59^{* * *}$ & $.69^{* *}$ & & & & & & & \\
\hline 4 & Training process & $.49^{* *}$ & $.22^{* *}$ & $.25^{* *}$ & & & & & & \\
\hline 5 & Job performance & $.28^{* *}$ & $.25^{* *}$ & $.12^{*}$ & $.50^{* *}$ & & & & & \\
\hline 6 & Training eff. & $.51^{* * *}$ & $.42^{* *}$ & $.31^{* *}$ & $.64^{* * *}$ & $.57^{* *}$ & & & & \\
\hline 7 & EBM & $.50^{* *}$ & $.55^{* *}$ & $.48^{* *}$ & $.36^{* * *}$ & $.39^{* *}$ & $.52^{* * *}$ & & & \\
\hline 8 & SDBM & $.35^{* *}$ & $.53^{* *}$ & $.50^{* *}$ & $.35^{* *}$ & $.39^{* *}$ & $.40^{* * *}$ & $.66^{* *}$ & & \\
\hline 9 & SIBM & $.34^{* *}$ & $.50^{* *}$ & $.42^{* * *}$ & $.45^{* *}$ & $.21^{* *}$ & $.44^{* *}$ & $.58^{* *}$ & $.60^{* *}$ & \\
\hline 10 & Curriculum & $.41^{* *}$ & $.27 * *$ & $.29 * *$ & $.59 * *$ & $.37 * *$ & $.44 * *$ & $.46^{* *}$ & $.45 * *$ & $.48 * *$ \\
\hline
\end{tabular}

Note: $\mathrm{EBM}=$ expectancy-based management; $\mathrm{SDBM}=$ self determination-based management, SIBM = social identity-based management $\quad * * \mathrm{p}<0.01$

The mean and standard deviation of the respondents' scores were calculated. In general, from the three types of organizational culture, clan culture is the most dominant with an average value (M) of 4.19 while the adocracy culture is 3.80 and market culture is 3.92. From the aspect of training, the highest value variable is the training process with an average value of 4.34 and the lowest is performance with an average value of 4.00. When viewed from standard deviations (SD), the highest uniformity (lowest SD) is training curriculum (0.38). The answer with the lowest uniformity (highest SD) is performance (0.71) and adocratic culture (0.58). The most widely used training management model is social identity based management.

Table 3. Means and standard deviations of the study variables

\begin{tabular}{rlrr}
\hline Variable & M & SD \\
\hline 1 & Clan culture & 4.19 & 0.46 \\
2 & Adhocracy culture & 3.80 & 0.57 \\
3 & Market culture & 3.92 & 0.52 \\
4 & Training process & 4.34 & 0.45 \\
5 & Job performance & 3.99 & 0.71 \\
6 & Training effectiveness & 4.32 & 0.49 \\
7 & Expectancy-based Management & 4.03 & 0.51 \\
8 & Self determination-based management & 3.98 & 0.49 \\
9 & Social identity-based management & 4.16 & 0.48 \\
10 & Curriculum & 4.18 & 0.38 \\
\hline
\end{tabular}

After the above process is carried out, we proceed with running the CFA (Confirmatory Factor Analysis) on each variable. CFA with the value of AVE (Average Variance Extracted) below 0.5 and CR (Composite Reliability) below 0.8 immediately repeated by removing items with the lowest loading factor. The process is terminated if the AVE and CR have fulfilled the requirements or constructs reduced to two items, which is no longer possible for the CFA to be carried out. From this process, all culture constructs were reduced from 4 to 2 items, the curriculum was reduced to four items (AVE $=0.513$; CR $=0.804$ ), all trainig management cunstructs reduced from 3 to 2 items. The training process, effectiveness, and job performance number of items were not changed. $\mathrm{AVE}$ and CR for training process are 0.514 and 0.912 ; for training effectiveness are 0.663 and 0.854 ; and for job performance are 0.686 and 0.929 .

\section{Comparing the Fit of the Structural Models}


Nine alternative models were fit to the data to find the answer for the hypothesis. In model A (see Figure 1), we fit clan culture with expectation-based training management into the model. We found that clan culture didn't have relationship to any process and output variables. Meanwhile, training management did have positive effect to training effectiveness. Training curriculum have negative effect, depicted in red arrow, to training process. The model has $\chi^{2}$ probability 0.00; RMSEA 0.09; GFI 0.84; AGFI $0.75 ; \chi^{2} / \mathrm{df} 3.41$, TLI 0.79 , and CFI 0.85 .

In model $\mathrm{B}$, we fit clan culture with self determination-based training management. The relationship between variables became better. The model is not only aligned to have an impact on employee training and performance but maintains relationships that should occur between elements of training and employee performance. Statistical fit for this model is $\chi^{2}$ probability 0.00 ; RMSEA 0.10; GFI 0.92; AGFI 0.84; $\chi^{2} / \mathrm{df} 3.28$, TLI 0.88, and CFI 0.93 .

In model $\mathrm{C}$, we fit clan culture with social identity-based training management. This time there is a match between clan cultural effects and identity-based training management. Clan culture has a positive effect on the training process while training management based on identity theory has a positive impact on the effectiveness of training. Because the training process has a positive effect on training effectiveness, this means that clan culture and identity-based management together strengthen the effectiveness of training. Statistical fit for this model is $\chi^{2}$ probability 0.00 ; RMSEA 0.093; GFI 0.928; AGFI 0.855; $\chi^{2} / \mathrm{df} 3.13$, TLI 0.89 , and CFI 0.94 .

From the model comparison, the best management for clan culture depicted by Model B, which is determination-based management. This is because the model showed most significant paths than other model. Hence, hypothesis 1 which claim clan culture is the best organizational culture for social identity-based training management, depicted by Model C, is rejected.

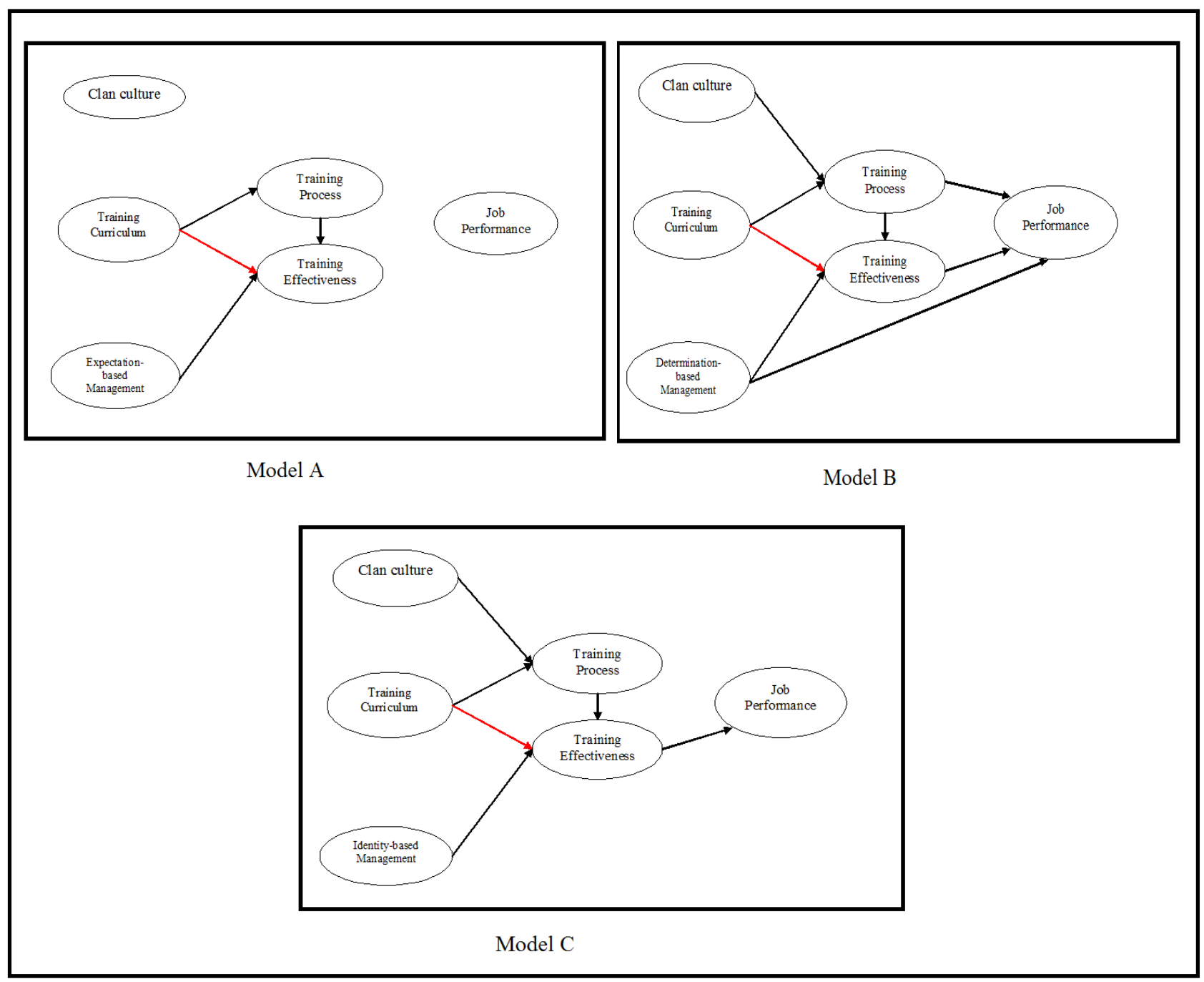

In model D (see Figure 2), we fit adhocracy culture with expectation-based training management into the model. The results obtained are that the culture of adocracy has no effect on training variables and performance while expectation training management 
has a positive effect on the effectiveness of training. The model has $\chi^{2} 0.00$; RMSEA 0.10 ; GFI 0.91; AGFI 0.82; $\chi^{2} / \mathrm{df} 3.87$, TLI 0.86, and CFI 0.92 .

In model E, we fit adhocracy culture with determination-based training management into the model. In this model, the culture of adocracy has no impact on both training variables and employee performance. In other words, it can be said that there is weak dissonance because the culture of the adocracy has no impact while identity-based training management has a positive impact. The model has $\chi^{2}$ probability 0.00 ; RMSEA 0.10 ; GFI 0.84 ; AGFI $0.76 ; \chi^{2} / \mathrm{df} 3.71$, TLI 0.81 , and CFI 0.86 .

In model $\mathrm{F}$, we fit adhocracy culture with identity-based training management into the model. It can be seen that in this model, the worst effects occur because the organizational culture of adocracy and identity-based training management do not have any effect on the aspects of training and employee performance. More than that, other variables are also not related to each other. Therefore, it can be concluded that the culture of adocracy is the worst if paired with identity-based training management. The model has $\chi^{2}$ probability 0.00; RMSEA 0.10; GFI 0.91; AGFI 0.82; $\chi^{2} / \mathrm{df} 3.61$, TLI 0.88, and CFI 0.93.

Hypothesis 2 states that adhocracy culture is the best organizational culture for self determination-based training management. From Figure 2, we see that the model (Model E) result not differ from Model A, which relates adhocracy culture with expectancy-based training management. Hence, hypothesis 2 rejected. Self determination-based training management did not superior than expectancy-based training management for improving process, effectiveness, and job performance.

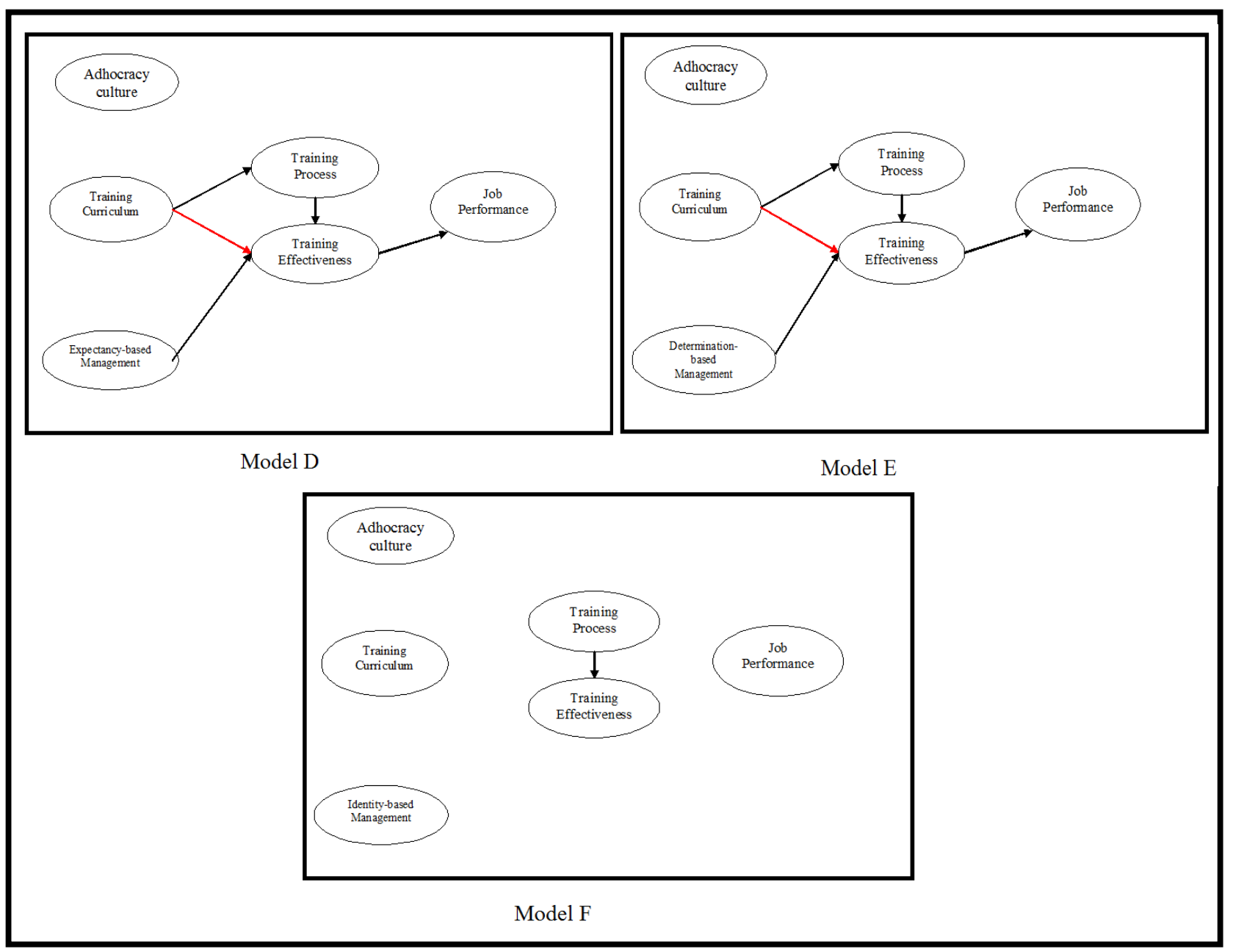

In model $\mathrm{G}$, we use market culture and pair it with expectancy-based management. In this model, market culture does not give effect to training but directly to employee performance and this relationship is negative. The more organizations oriented to the market, the lower the employee's performance. Even so, expectations-based training management has a positive effect on training effectiveness, which in turn has a positive impact on employee performance. As a result, market culture and expectation-based management out of alignment because one has a negative effect while another has a positive effect. The model has $\chi^{2}$ probability 0.00 ; RMSEA 0.07; GFI 0.95; AGFI 0.91; $\chi^{2} / \mathrm{df} 2.22$, TLI 0.94, and CFI 0.97.

In model $\mathrm{H}$, we still use market culture, but change the management to determination-based. When training management indicators are changed to based on determination, the relationship that occurs can be seen in Figure 3. Market culture continues to experience dissonance with training management based on determination. The model has $\chi^{2}$ probability 0.00 ; RMSEA 0.09; GFI 0.93; AGFI $0.86 ; \chi^{2} / \mathrm{df} 3.17$, TLI 0.88 , and CFI 0.94 . 
In model I, market culture paired with social identity-based training management. It is seen that the position of market culture and identity-based training management has not changed. Both relations remain antagonistic. Therefore, it can be concluded that market culture does not have a preference for certain training management models. In general, the market model is contradictory in giving effect to training output and employee performance compared to training management. The model has $\chi^{2}$ probability 0.00 ; RMSEA 0.09; GFI 0.94; AGFI 0.87; $\chi^{2} / \mathrm{df} 2.86$, TLI 0.91, and CFI 0.94.

Hypothesis 3 states that market culture is the best organizational culture for expectancy-based training management. The hypothesis is not supported. Market culture actually best fit with self determinacy-based training management. Hence hypothesis 3 rejected.

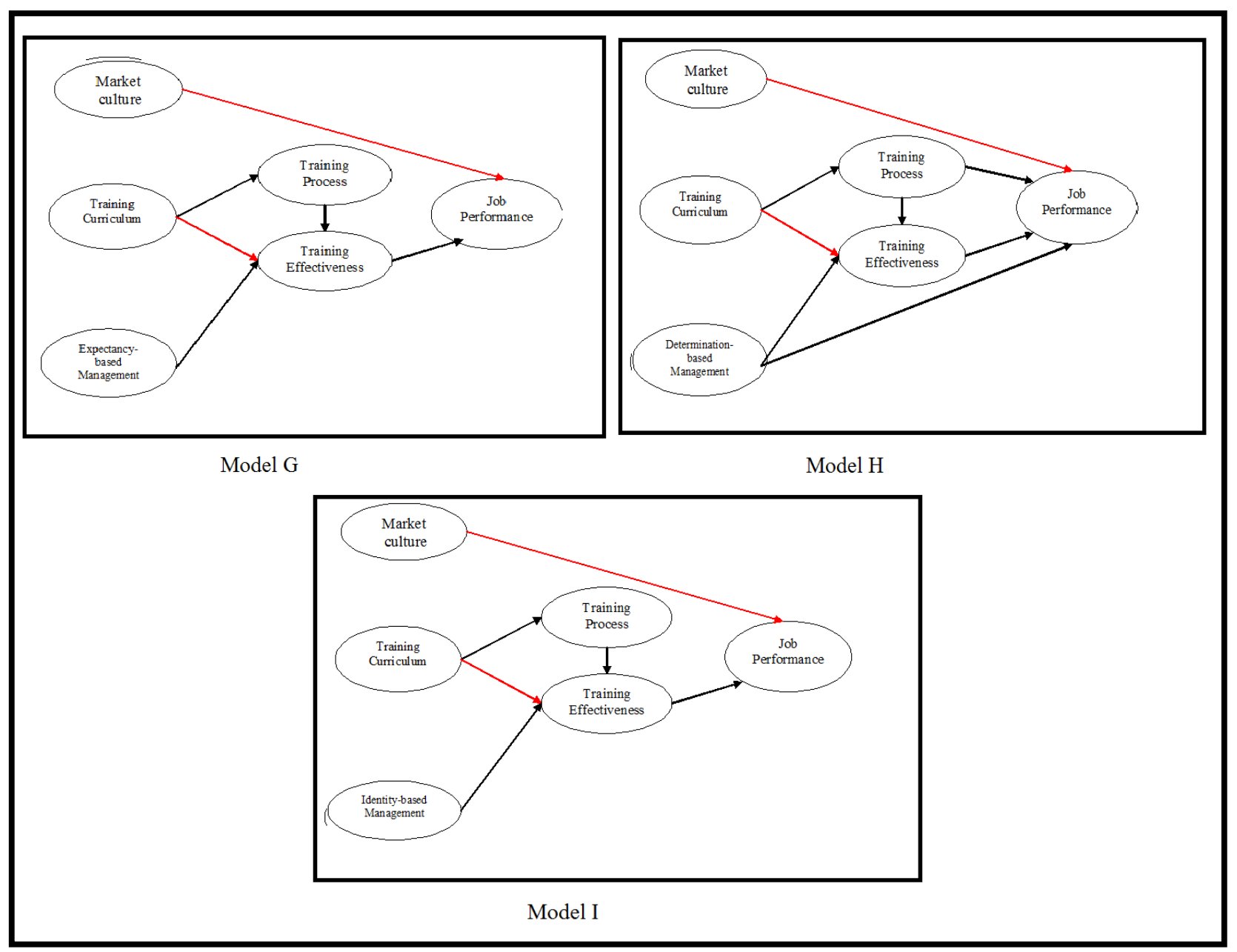

Accordingly, all the hypotheses about the fit between organizational culture and training management rejected. However, this means there is one superior training management which universal for all cultures. From Figure 1, we can see determination-based management results in most relationship expected under clan culture. Figure 2 also show that determination-based management at least as good as expectancy-based management under adhocracy culture. Meanwhile, in Figure 3, market culture best fit with determination-based management. Hence, the primary objective of this research met. The best theory to support training management effort is self determination theory.

As shown in Figure 1, 2, and 3, we can get some interesting results. First, organizations with a market culture always have a negative influence on employee performance, no matter whether management training is used on the basis of expectations theory, theory of determination, or identity theory. But if you really have to choose the right training model, the most appropriate model must be based on the theory of determination. As Figure 3 shows, this training model is able to have a positive effect on employee performance from three paths, namely training management, training processes, and training effectiveness.

Second, organizations with an adocratic culture do not have an impact on employee performance so training with any model can be held. When viewed from the impact on employee performance, the best training model is a training model based on the theory of determination or expectation theory. Curriculum and management on the basis of these two theories will have an effect on the process and effectiveness of training and have an impact on employee performance. The identity theory-based training model must be avoided because it does not have an impact on employee performance. 
Third, organizations with clan culture can have a positive influence on employee performance but only indirectly and even this must be paired with training management based on determination or identity. Expectancy-based training management does not provide benefits to employee performance in organizations with clan culture. The best training model in clan culture is training management based on the theory of determination.

Lastly, without looking at organizational culture, the best management training is training management based on the theory of determination. Training management based on the theory of determination is able to effect the process and effectiveness of training as well as on employee performance.

Previously it was hypothesized that market culture best fits expectations-based management, culture of adocracy with management based on self-determination, and clan culture with management based on social identity. This is based on environmental training theory which states that organizational culture will have an impact on the process and output of training, so a review of organizational culture is needed before compiling curriculum and management of training (O'Halloran, 1991). Basically, organizational culture will have an impact on various problems of external adaptation and internal integration (Vijayakumar \& Padma, 2014) and training is a form of internal integration. Furthermore, this is also based on the competing values theory of (Vijayakumar \& Padma, 2014) because cultural values must be in harmony with the management pattern so that no opposite values occur.

The results show that market culture is precisely in accordance with management based on self-determination contrary to hypothesis. Meanwhile, the results show that the adocratic culture is most in line with the management of self-determination and expectation that is still in line with the view that management of self-determination is a model that is compatible with the culture of adocracy. But the findings that in the clan model, management of self-determination is most in line creates a difference with the hypothesis that identity management is the most appropriate.

Market culture is hypothesized by expectation-based theory because this management system focuses on expectations for obtaining a broad market. Expectation theory is used because this theory targets the economic rational aspects of humans, as well as market cultures that try to gain economic benefits. The fact that appropriate management is based on the theory of self-determination reflects that market culture builds competitiveness by elevating intrinsic motivation in employees to excel in business. This culture is a culture that induces competition (Pilch \& Turska, 2014) so that every employee must be encouraged to compete using their respective intrinsic motivations. Management based on self-determination stimulates the psychological need for self-autonomy as a facilitator for intrinsic motivation (Chen \& Lin, 2010). This means that market culture is more trying to manage training by encouraging employees to achieve autonomy for independent and high performance. Although autonomy is more inclined to efforts to manage creativity as in the culture of adocracy, autonomy is indeed contrary to collectivity, as well as market culture that is contrary to clan culture.

Adocratic culture is hypothesized to use management of self-determination because adocracy is oriented towards innovation, in accordance with self-determination that demands autonomy. The theory of self-determination leads to emotional aspects such as courage in taking risks. Adocracy culture prioritizes decentralization of decision making, creativity, entrepreneurship, and risk taking (Leahy et al., 2014). Self-determination provides innovative norms as values that allow individuals to explore and use autonomy to address organizational issues (Oyefolahan \& Mahmud, 2013).

Clan culture is hypothesized to use social identity management, but the results of the study also show that management based on self-determination is more in line with clan culture. In clan culture, personal identity and social identity try to be equalized. This is interesting because clan culture prioritizes collaboration, in accordance with the sociological dimensions of social identity theory, in contrast to the norms of self-determination that emphasize autonomy. However, another aspect of clan culture is standardization, formalization, and centralization as well as employee participation to meet the demands of a rapidly changing environment (Fry, 2003). For new employees, this is actually expected because they still do not have the confidence to make changes radically and independently. This research was conducted in the context of the apprenticeship program for mining companies in South Sulawesi. An apprenticeship program is an education or training program for new employees to prepare it for their company's first job.

Management based on self-determination serves as a counterweight so that the organization does not overemphasize fearbased bureaucracy (Fry, 2003) but produces a kind of bureaucracy that triggers intrinsic motivation through competence and relevance, not through autonomy. Competence, autonomy, and relevance are three features of the theory of self-determination (Fry, 2003). Competence in new employees rests on centralization because with centralization, clear indicators and rigorous evaluations can limit how one is expected to achieve. This clarifies the direction in which an employee must act so that he can achieve the desired achievement. Similarly, new employees need a sense of relevance, where they are considered part of the work group and are recognized as employees in their new company.

Our results suggest that a management model that is compatible with various organizational cultures is a management model based on the theory of self-determination, characterized by a trainer who emphasizes the pleasant aspects of the work to be done, the trainer who comes from a well-known external organization, and motivates participants based on their personal characteristics. Although training management based on social identity theory and expectation theory is also proposed as an alternative variable, management variables based on self-determination can be accepted on all models of organizational culture. Therefore, self determination-based management need to be considered when studying training outcomes.

Training management is the main field of HR development. Although further research is still needed to confirm and expand this research, the present findings are in line with theory and research regarding the contribution of training to employee performance. Combined with the literature on organizational culture and motivational theories, this study affirms the idea that trying to train new 
employees through the pattern of apprenticeships has positive benefits for employees. As mentioned earlier, the training process of apprenticeships can improve the effectiveness of training, which in turn improves employee performance. This finding, in line with environmental training theory, extends the suggested benefits of training programs beyond the training of old employees, by involving positive implications for new employees.

There is a consensus that training must be adapted to organizational culture in order to achieve optimum results. Our results suggest that there are one of the best cultures to produce a training process, namely clan culture. Clan culture is characterized by an orientation in building relationships between people and well-formed relationships that will be able to provide a training process where the trainees are friendly, accept each other, and help each other so that all participants understand each other. The atmosphere of this family-like training process has an impact on the effectiveness of training which in turn leads to employee performance. Throughout the course of the training process, management directs a situation of self-determination, where employees are encouraged to see that the work they will get is more fun. Social aspects are often ignored in training that is only oriented to the transfer of knowledge or skills, but this social aspect has proved important in the context of the apprenticeship, and should be applicable in similar training in various places outside the mining sector. However, this could be unique to collectivistic culture such as Indonesia. Further research needs to be taken in individualistic culture.

Further, this study provides guidance for companies and organizations in organizing apprenticeship program. In order to provide maximum results, this program must be carried out in a family-like culture of clans, guided by an up-to-date curriculum in accordance with real conditions in the field, and motivating using self-determination approach. Clan culture and self-determination work to balance each other. Self-determination prevents the training situation from being merely a suave atmosphere by providing clear targets related to expected performance, competencies needed, and clear differentiation between which are social and which are autonomous. Clan culture prevents stressed self-determination from leading to a dry situation, which brings employees to competition and selfishness for personal gain and ignores aspects of cooperation and socialization.

\section{CONCLUSION}

The results of this study indicate that self determination theory may be the best theory to support training management intervention across diverse organizational culture contexts. When implemented in training management, self determination theory may provide the trainers and organizations the best way to achieve high quality training process, better training effectiveness, and higher job performance as a results of training transfer. The current results should informs competing theories to show their abilities to serve training better outcomes that self determination theory could provide.

\section{LIMITATIONS AND DIRECTIONS FOR FUTURE RESEARCH}

Our methodology have some limitations. This research relies on self reports and survey data. This can lead to bias in the general method. Common method bias occurs when one has to answer all the questionnaire all by him/herself. General method bias can increase correlation or have an improper effect on hypothesized relationships. The correlation table reported in the results chapter show a thorough correlation on the research variables, although relatively consistent with expectations. Hence, that bias can play a role. This is especially true if the variables studied are perceptual. Employee performance variables, for example, are more suitable if reported by others, such as supervisors or superiors, rather than by the respondents themselves.

Because possible general method bias, further research needs to use additional data collection strategies or use other output variables, such as motivation or intention to transfer training or the training transfer variable itself.

We also use cross-sectional data collection method. Ideally, research involving an intervention, especially training, uses data before and after so that the effectiveness of training can be obtained from objective and longitudinal data. In order to obtain a more valid picture of the attenuation and causal effects in this research model, further research needs to use a more robust research design such as longitudinal analysis. For example, because training management, training processes, and training effectiveness are not experiences at the same time, it is very necessary for these three variables to be measured at different times according to the longitudinal research design with pre and post test.

\section{REFERENCES}

[1] Ajzen, I. (1991). The theory of planned behavior. Orgnizational Behavior and Human Decision Processes, 50, $179-211$. https://doi.org/10.1016/0749-5978(91)90020-T

[2] Andersson, T. (2012). Normative identity processes in managers ' personal development training. Personnel Review, 41(5), 572589. https://doi.org/10.1108/00483481211249111

[3] Bjerregaard, K., Haslam, S., \& Morton, T. (2016). How identification facilitates effective learning: the evaluation of generic versus localized professionalization training. International Journal of Training and Development, 20(1), 17-37.

[4] Bondarouk, T., \& Ruel, H. (2010). Dynamics of e-learning: theoretical and practical perspectives. International Journal of Training and Development, 14(3), 149-154. 
[5] Carvalho, A., Melo, S., \& Ferreira, A. (2016). Training in Portuguese non-profit organizations: the quest towards professionalization. International Journal of Training and Development, 20(1), 78-91.

[6] Chen, M. Y.-C., \& Lin, C. Y.-Y. (2010). Dose transformational leadership facilitate SBU innovation? The moderating roles of SBU culture and incentive compensation. Retrieved from http://nccuir.lib.nccu.edu.tw/handle/140.119/41287

[7] Chiang, C., Jang, S., Canter, D., \& Prince, B. (2008). An expectancy theory model for hotel employee motivation: Examining the moderating role of communication satisfaction. International Journal of Hospitality \& Tourism Administration, 9(4), 327351.

[8] Crow, S. D. (2007). An Evaluation of Organizational and Experience Factors Affecting the Perceived Transfer of U.S. Air Force Basic Combat Skills Training. Air University.

[9] Dodge, D., \& Ramsey, J. (1981). Employee Motivation. Journal of Library Administration, 1(3), 43-54.

[10] Dysvik, A., \& Kuvaas, B. (2008). The relationship between perceived training opportunities, work motivation and employee outcomes. International Journal of Training and Development, 12(3), 138-157.

[11] Elangovan, A., \& Karakowsky, L. (1999). The role of trainee and environmental factors in transfer of training : an exploratory framework. Leadership \& Organization Development Journal, 20(5), 268-276.

[12]Ferris, G. R., Hochwarter, W. A., Buckley, M. R., Harrell-Cook, G., \& Frink, D. D. (1999). Human resources management: Some new directions. Journal of Management (Vol. 25). https://doi.org/10.1177/014920639902500306

[13]Fry, L. W. (2003). Toward a theory of spiritual leadership. Leadership Quarterly, 14(6), $693-727$. https://doi.org/10.1016/j.leaqua.2003.09.001

[14] Gagne, M. (2012). The Motivational Leadership Training Program.

[15] Gil, A. J., Molina, J., \& Ortega, R. (2016). Determinants of training transfer in the wine industry: conceptual hypotheses and results for Rioja (Spain). Journal of Wine Research, 27(1), 65-83. https://doi.org/10.1080/09571264.2015.1116440

[16] Heaney, C. A. (1991). Enhancing Social Support at the Workplace: Assessing the Effects of the Caregiver Support Program. Health Education \& Behavior, 18(4), 477-494. https://doi.org/10.1177/109019819101800406

[17] Korte, R. F. (2007). A review of social identity theory with implications for training and development. Journal of European Industrial Training, 31(3), 166-180. https://doi.org/10.1108/03090590710739250

[18] Lacerenza, C. N., Reyes, D. L., Marlow, S. L., \& Joseph, D. L. (2017). Leadership Training Design, Delivery, and Implementation : A Meta-Analysis. Journal of Applied Psychology, 102(12), 1686-1718.

[19] Leahy, M. J., Chan, F., Lui, J., Rosenthal, D., Tansey, T., Wehman, P., ... Menz, F. E. (2014). An analysis of evidence-based best practices in the public vocational rehabilitation program: Gaps, future directions, and recommended steps to move forward. Journal of Vocational Rehabilitation, 41(2), 147-163. https://doi.org/10.3233/JVR-140707

[20] Mazenod, A. (2016). Education or training? A comparative perspective on apprenticeships in England. Journal of Vocational Education and Training, 68(1), 102-117. https://doi.org/10.1080/13636820.2015.1117521

[21] O'Halloran, R. (1991). Management Training Theories: Tools for Hospitality Managers and Trainers. Hospitality Review, 9(1), 67-84. Retrieved from http://digitalcommons.fiu.edu/hospitalityreview/vol9/iss1/7

[22] Oyefolahan, I. O., \& Mahmud, M. (2013). Research framework on KMS use: An approach anchored on the interplays between engineered and emergent organizational factors. International Conference on Research and Innovation in Information Systems, ICRIIS, 2013, 370-373. https://doi.org/10.1109/ICRIIS.2013.6716738

[23] Palthe, J., \& Kossek, E. E. (2003). Subcultures and employment modes: Translating HR strategy into practice. Journal of Organizational Change Management, 16(3), 287-308. https://doi.org/10.1108/09534810310475532

[24] Pilch, I., \& Turska, E. (2014). Relationships Between Machiavellianism , Organizational Culture , and Workplace Bullying: Emotional Abuse from the Target, $\mathrm{s}$ and the Perpetrator' $\mathrm{s}$ Perspective. Journal of Business Ethics, 83-93. https://doi.org/10.1007/s10551-014-2081-3

[25] Pruekpramool, C., \& Sangpradit, T. (2016). Teaching Physics in English: A Continuing Professional Development for NonNative English-Speaking Teachers in Thailand. Journal of Education and Learning, 5(2), 47. https://doi.org/10.5539/jel.v5n2p47

[26] Racelis, A. D. (2005). An Exploratory Study of Organizational Culture in Philippine Firms. Philippine Management Review, 12, $72-86$.

[27] Reio Jr, T. G. (1997). Effects of Curiosity on Socialization-Related Learning and Job Performance in Adults. Virginia State University.

[28] Ryan, R., \& Deci, E. (2000). Self-determination theory and the facilitation of intrinsic motivation. American Psychologist, 55(1), 68-78. https://doi.org/10.1037/0003-066X.55.1.68

[29] Swanson, R., \& Holton, E. (2001). Foundations of human resource development. Berrett-Koehler.

[30] Vijayakumar, V. S. R., \& Padma, R. N. (2014). Impact of perceived organizational culture and learning on organizational identification. International Journal of Commerce and Management, 24(1), 40-62. https://doi.org/10.1108/IJCoMA-01-20120003 
